\title{
Making Sense of Material Culture Transformation: A Critical Long-Term Perspective from Jomon- and Yayoi-Period Japan
}

\section{Koji Mizoguchi ${ }^{1}$}

Published online: 19 March 2020

(C) The Author(s) 2020

\begin{abstract}
This JWP Focus paper argues that material culture transformation can be understood as the transformation of the way human beings and material culture mutually open up their potentialities. Such opening up/becoming takes place in the domains of their encounter, which often take the form of human communications. In communication, human beings and material culture mutually mediate/intervene/transform their modes of existence as the former cope with various uncertainties and risks that the world generates and that communication differentiates. Drawing upon the theory of communication developed by the social systems theorist, Niklas Luhmann, the paper will elucidate and elaborate this perspective through an examination of the long-term transformation of the mode of such mutual opening up/becoming by human beings and the material culture of their potentialities that took place in the Jomon and the Yayoi periods of Japan between 13000 Cal BC and AD 250/300.
\end{abstract}

Keywords Material culture · Transformation · Communication · Luhmann · Jomon · Yayoi

\section{Introduction}

This paper puts forward a novel perspective on the explanation and understanding of the long-term transformation of material culture by critically connecting some fruits of the 'material culture turn' in archaeology (e.g. Hicks 2010) with the sociologist and social systems theorist Niklas Luhmann's theory of communication systems (Luhmann 1995, 2012, 2013).

One characteristic shared by a proportion of the proponents of the 'material culture turn' is the emphasis on symmetrical relationships between human beings

Koji Mizoguchi

mizog@scs.kyushu-u.ac.jp

1 Kyushu University, 744 Moto'oka, Nishi Ward, Fukuoka 819-0395, Japan 
and material culture. We have had a large number of nuanced theoretical attempts to capture the essence of a symmetrical relationship between human and material beings (e.g. Olsen 2010; Hodder 2012), and the widely shared points can be paraphrased thus:

(a) the human-material encounter makes certain faculties and potentialities of human beings and material culture, that is, their faculties and potentialities of bringing transformations of various natures, scales and temporalities to themselves and to the world, realized, and

(b) how this mutual constitution/realization, or mutual 'opening up', that constitutes and reveals their faculties and potentialities as a unified process (Heidegger 1993 [1960]) comes about can be safely assumed to be significantly constituted by the context in which such an encounter takes place and a mutual opening up unfolds.

It can be said that the above theses significantly contributed to bringing material culture, one of the definitional subjects of the discipline of archaeology, back to the focus of our attention; material culture is 'active' not only in that it can actively and strategically be mobilized by human 'agents' to conduct their acts and realize the consequences they desire (e.g. Hodder 1982), but in that it has its own 'agency' that can influence the way in which human beings live their lives (Gell 1998). After all, as so-called speculative realist philosophers such as Graham Harman (2011) emphasize, material things have certain elements and properties which human beings can never grasp or perceive, hence human beings are never quite able to access and gain control over such elements. At the same time, material things are transformed with or without any human interventions/encounters, and the transformed elements that can never be grasped or perceived by human beings might transform the ways in which human beings feel, think and/or do things, with or without them knowing it.

How to incorporate this newly recognized 'independence' of material culture into our archaeological endeavor is now widely recognized as an important challenge for archaeologists (cf. Olsen et al. 2012). I would particularly like to argue that how we relate this to our making sense of changes and transformation that we recognize archaeologically in past material evidence and that we reconstruct in past human behavior is of crucial importance, because, as material culture is a definitional subject of archaeology, the ability to deal with long-term change/ transformation is also what makes archaeology unique in human and social sciences.

However, long-term change/transformation is the topic which is given insufficient attention, and sometimes virtually ignored, in its morphological-stylistic characteristics in particular, by prominent proponents of the material culture turn in archaeology (e.g. Olsen 2010); although it has to be emphasized that they do not ignore the importance of temporality and change completely. For instance, in his seminal work, Bjørnar Olsen touches upon differential categories/units of temporality/duration in relation to the ways in which they are memorialized through materialization. However, he does not connect them to the temporal 
change/transformation of material culture items themselves (Olsen 2010, pp. 107-128; and the index of this volume does not include such words as 'change' and 'transformation': see Olsen 2010, pp. 197-201).

Let me consider the work of another influential figure. In his innovative work on the symmetrical relationship between humans and things, Ian Hodder emphasizes the crucial importance of the 'selective context' (Hodder 2012, pp. 145-146, especially the first paragraph of p. 146) for the explanation of changes in human-material interconnection/interdependence (which he describes as 'entanglement'). In such a selective context, according to Hodder, various material cultural and human behavioral traits gain differential degrees of persistence through a somewhat Darwinian evolutionary selective process, and such differences, emerged between the entangled mental, material and behavioral units in their functional efficiency, make the sustenance of a certain entanglement difficult (he puts it thus: 'small things do go wrong every now and then': Hodder 2012, p. 200), leading to a change or changes in what things are entangled and in the way they are entangled (Hodder 2012, pp. 145-146). Deriving from this model, Hodder further argues that mental, material and human behavioral change/transformation can be understood as the contingent, sequential changes of the emergent potentiality of entanglements (Hodder 2012, pp. 179-205). However, in his detailed case studies describing how certain events/trends led to a sequence of changes in the way the ever-changing range of things, human thoughts and behavioral patterns were entangled (cf. Hodder 2012, Chapter 9), causal processes between what went wrong and what reactions took place, and why certain reactions rather than others stayed/became adopted are not satisfactorily specified. Hodder elegantly shows the co-occurrence of changes between mental, material, and behavioral units. However, when it comes to the specification of the cause $(s)$, his argument remains inferential, and the procedure he adopts is haphazard. These problems, I would argue, significantly derive from his failure to sufficiently theorize the way in which the 'selective context' (mentioned above) constitutes/ influences the way certain mental, material and behavioral units were causally entangled. (We shall remedy this particular problem by introducing the sociologist Niklas Luhmann's theory of communication systems: see below.)

After all, what we would like to identify, when we do archaeology in the hope of obtaining wisdom for the present and for the future, is a patterned/recurrent causal connection between different categories of happenings, both the mental and the material, and Hodder's attempt at relating the symmetrical relationality between things and humans to its historical long-term transformation, one of the most advanced and sophisticated, falls short of realizing this objective.

In order to tackle the issue of long-term material culture change and transformation, I would like to translate/transform the theses concerning how to grasp symmetrical relationships between human and material beings mentioned above as follows:

(x) the human-material encounter is the continuous, mutual creation of differences, that is, differences between what human beings and material culture were like at Time $\mathrm{T}$ and what they are like at Time $\mathrm{T}+1$ (such process can be described 
as 'becoming': see Deleuze and Guattari 1987), and some such differences constitute problems which human beings need to react to and cope with, and

(y) the way such differences and problems emerge, and the way human beings react to and cope with them are significantly constituted by the context in which such emergences and coping take place.

By ontologically premising them, I would like to tentatively lay out the theoretical premise of and tasks for this paper thus:

(1) human individuals would have coped with various sets of issues and difficulties, and such coping would have constituted the manner in which they thought and did things, that is, perceiving the sources of those issues and difficulties and handling them, and would have shaped the things which helped their coping, that is, material items of various characters and scales;

(2) we have to situate such copings, their material mediation, and the mutual becoming of human individuals and material items in their unique spatio-temporal contexts/domains, often taking the form of communication systems (for the definition of the concept given by Niklas Luhmann, see below);

(3) we have to understand how such contexts, or communication systems, are constituted by/connected to what factors, and how;

(4) we have to investigate the transformation of the mode of the mutual becoming of human beings and material culture in relation to the long-term transformation of individual communication systems, their socio-cultural/natural environments, and the way in which they were interconnected.

As illustrated later, I find the sociologist Niklas Luhmann's theory of communication systems one of the most effective guiding frameworks for such an undertaking (Luhmann 1995, 2012, 2013), particularly in terms of understanding the concrete mechanism and the process of the constitution of the 'selective context' mentioned above (Hodder 2012, pp. 145-146) and causal contextuality of the mutual becoming of human beings and material culture (tasks 2 and 3 above) and the mechanism of the transformation of material culture in terms of the transformation of the mode of the mutual becoming of human being and material being (task 4).

It has to be noted that Luhmann's conceptualization of communication systems is quite close to John Barrett's concept of 'fields of discourse' (Barrett 1988). Luhmann's theory is widely recognized as one of the grand social theories (Joas and Knöbl 2009), standing side by side with the structuration theory of Anthony Giddens (Giddens 1984) and the theory of communicative action of Jürgen Habermas (Habermas 1984). Focusing on the elements of this grand theoretical framework which I draw upon, they effectively expand the horizon covered by Barrett's. Barrett's fields of discourse theory focuses on the way society and sociality are constituted through the recursive movement of individual agents through a certain range of the fields of discourse constituting a social whole (Barrett 1988). In that sense, Barrett's theory is not necessarily designed to address issues concerning the diachronic process and mechanism of the long-term transformation of society. Luhmann's 
theory, as I will illustrate below, includes a framework that theorizes in detail how communication systems change/transform themselves through selectively reacting to what happens to their respective environments (consisting of the other systems and various other social and natural environmental factors).

Admittedly, Luhmann does not pay sufficient attention to the way communication is mediated, made possible, and constituted by material culture, and to the way such mediation of, support for, and constitution of communication by material culture transforms material culture itself. Therefore, an important task to be undertaken in the explication of the theoretical framework which the current paper draws upon in the next chapter is to firmly connect his theory to material culture.

\section{Theoretical Framework}

Niklas Luhmann, the sociologist who established an advanced systemic theoretical paradigm for the explanation and understanding of society and social phenomena (Luhmann 1995, 2012, 2013), grasps that any entity which can be described as a system reproduces itself. Such entities, according to Luhmann, include living organisms, human minds (Luhmann calls them 'psychic systems'), communications, organizations and societies (Luhmann 1995, Introduction). He also grasps that such self-reproduction goes on by the system continuously differentiating itself from its environment by selectively reacting to the differences generated in its environment (Luhmann 1995, chapters 4 and 5). In other words, a system reproduces itself by reducing the complexity of the world that the system itself differentiates. A system does so by reproducing the boundary between itself and its environment, and uses it as a filter with which to both shut out information on certain differences generated in the environment as noises, and to let through information on certain differences generated in the environment as being significant. Importantly, the differentiation of information into the 'noise' and 'significant' categories is made in a self-referential manner, that is, made by referring to how such differentiation was undertaken by itself in the past, and the functional value of the differentiation is determined by whether a differentiation is useful or harmful for the reproduction of a given system. This is revealed only through the subsequent operation of the system, and is evaluated in terms of whether the differentiation contributes to the reproduction of the system and how.

This and the following explication might make the reader wonder if there is any relevance in Luhmann's theorization to the archaeological study of material culture and materiality. In fact, there is plenty: the complexity of the environment of a communication, which the communication reduces to make it manageable, is comprised of material differences ranging from expressions of emotions through portable material items to environmental-topographical features, all of which have the quality of 'being in place' (see Olsen 2010, pp. 158-160). The boundary of a communication system is marked with such material differences as certain words and gestures, as well as material items. Additionally, all the material differences involved in the reproduction of a communication as the boundary markers and that existing as the material components of the environment are mutually linked in various 
and ever-changing ways and transformed through communication (Olsen 2010, pp. 158-160). The mutual 'opening up' of human beings and material culture, and their 'becoming' (mentioned above), can be captured in its concrete nature in this manner.

Luhmann grasps that communication is a system which reproduces itself in the aforementioned manner. According to him, communication consists of three components: information, expression, and understanding. A piece of information is chosen by him/her (the 'ego') to be expressed. The ego chooses how to express it to his/her counterpart (the 'alter'). In perceiving the expression chosen by the ego, the alter chooses to perceive it to be a certain expression for communication and chooses how to make sense of that expression, which takes the form of a material difference which is generated in the world. That 'making sense' takes the form of choosing how to connect the expression as a signifier to what is signified. Then the alter chooses how to react to what s/he understands.

Luhmann's grasping/theorization as to how communication works implies the following. His whole argument is highly complex, so let us itemize the points relevant to the investigation and argumentation to follow:

(1) the ego cannot know what choice the alter would make when the ego initiates a communication;

(2) the ego cannot know what choice the alter made when the alter reacts to ego's expression: the ego can only estimate/infer whether what ego meant was understood by the alter;

(3) what the ego can do is to assume what ego meant was understood/not understood by the alter and choose how to react to the alter's expression reacting to ego's initial expression;

(4) in this way, communication continues;

(5) in the continuation of communication, as the above shows, no one involved in it can be sure if they understand one another;

(6) in actuality, the continuation of communication takes the form of an expression (e.g. actions, utterances, gestures, facial expressions, and so on) being connected to the next, and to the next, and to the next ...;

(7) in order for a communication to continue, those who are involved in it need to have expectation as to how the alter would react to her/his expression and expectation of expectation as to how the alter expects him/her to act in a given circumstance and in reaction to the alter's expression (the combination of the expectation and the expectation of expectation is hereinafter simply called the expectations [in italic]);

(8) this is particularly so when a communication has to be re-initiated after a certain length of interval;

(9) it is relatively easy to share the expectations when those who are involved in a certain communication are fixed (i.e., stay unchanged) and the communication takes place frequently, because the expectations can be generated through the communication itself and they are internalized through the communication;

(10) the sharing of the expectations becomes difficult when the experiences of those who communicate with one another, or their biographies, vary; 
(11) the sharing of the expectations also becomes difficult when those who communicate are not fixed and their communication takes place infrequently;

(12) in order for the expectations to be established and maintained, they need to be connected to certain symbolic material media/material differences (certain mental, material and behavioral units become 'entangled' this way through a communication that works as a 'selective context' in Hodder's sense: see above);

(13) such symbolic material media are often that which mark the boundary between a communication and its environment;

(14) such symbolic media became generated, transformed and/or discarded/disappeared as the following factors changed: (A) the rate of the unfixed-ness/fluidity of those who are involved in a range of communications; (B) the frequency of their occurrence; and $(\mathrm{C})$ the scale of the spatio-temporal horizon which the communication needs to cover.

By adopting this framework we can examine in a concrete manner the process of the mutual constitution/opening up by material and human beings of their particular properties and potentialities, and that generates certain 'issues', or difficulties in the continuation of communication, with which those who communicate then have to cope. Such issues often emerge in forms that are unexpected/unpredictable. The beginning of the procurement and consumption of new resources (new things and new beliefs), for instance, would have generated new types of unexpected/unpredictable happenings in the form of new types of physical accidents, resource shortages, and conflicts. To cope with them, both the human and material beings have to become different from their former selves/states. Such coping takes the form of the mutual opening up that continually occurs through communication, so as to reduce the complexity of its environment, which is a prominent source of such uncertainties and risks.

The case study that follows can be characterized as an attempt to trace the longterm history of such coping by human and material beings with changing uncertainties and risks through the mutual opening up of their properties and potentialities, or through their becoming.

\section{Case Study}

Let us now examine how changes that happened in the course of the long-term historical trajectory from the Jomon to the Yayoi period in the Japanese archipelago can be explained and understood through the adoption of the concepts and framework illustrated above. An especial focus is placed upon pottery, one of the most common material items that archaeologists study (Fig. 1). 

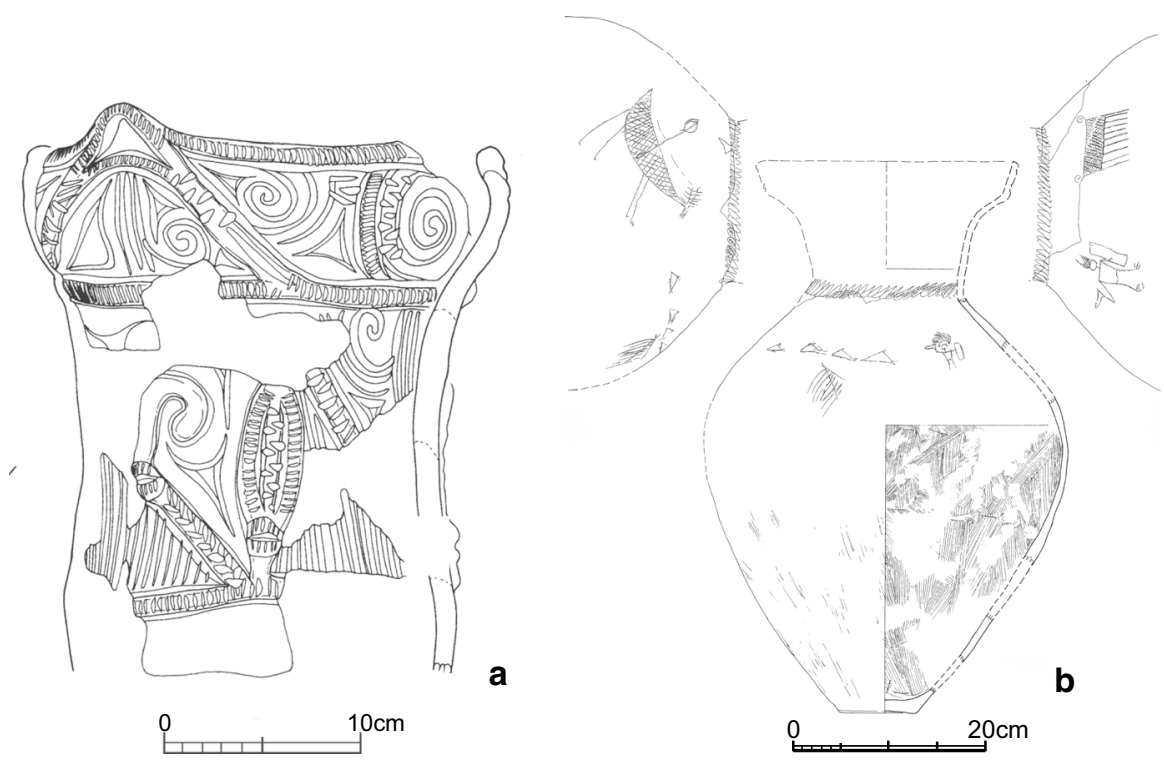

Fig. 1 Jomon and Yayoi pottery: a Early Middle Jomon (Katsusaka style) vessel from Pit dwelling No. 33, Tama new-town, site No. 245 (from Tokyo Metropolitan Centre for Buried Cultural Properties 1988, p. 135, Figure 110); b Late Middle Yayoi (Yayoi IV phase) vessel from the Shimizukaze site, Nara Prefecture (from Society of Yamato Yayoi Culture 2003, p. 122, Fig. 62)

\section{The Jomon Period}

The Jomon period of Japan is famous for its highly sophisticated hunter-gatherer communities (e.g. Habu 2004). However, in its Incipient and Initial Phases (c. $13000 \sim 10000$ cal BC, and $10000 \sim 5000$ cal BC, respectively: Kudo 2012), broadly co-terminous with the earlier Holocene, the settlement distribution and the ephemerality of the dwellings within those settlements, along with the hunting-tool-dominated lithic assemblage, suggest that highly mobile lifeways were pursued by smallscale communities (e.g. Imamura 1996, pp. 56-57, 88-91). The gradual shift to a sedentary way of life began at the end of the Initial phase, around $5000 \mathrm{BC}$, and from the Middle phase on, from around 3500 BC, a collector-system-type mobility mode (Binford 1980, pp. 10-13) appears to have developed: large settlements, probably functioning as 'bases', were located at fairly regular intervals, surrounded by much smaller settlements (Taniguchi 2005). A set of one large settlement and a number of small settlements surrounding it appears to have formed a loosely-defined territorial unit, possibly occupied by a corporate grouping of some sort (Taniguchi 2005). The 'base' type settlements (hereinafter 'base settlements') typically took a circular form, with the central burial area surrounded by concentric circular zones occupied by various features, including storage facilities, facilities for ritual purposes, and pit dwellings (Fig. 2). The 'satellite' type settlements (hereafter 'satellite settlements') sometimes yield different tool-kit-type assemblages from one another (e.g. Kani 1993; Kobayashi 2004, pp. 113-116). They may have been permanently 


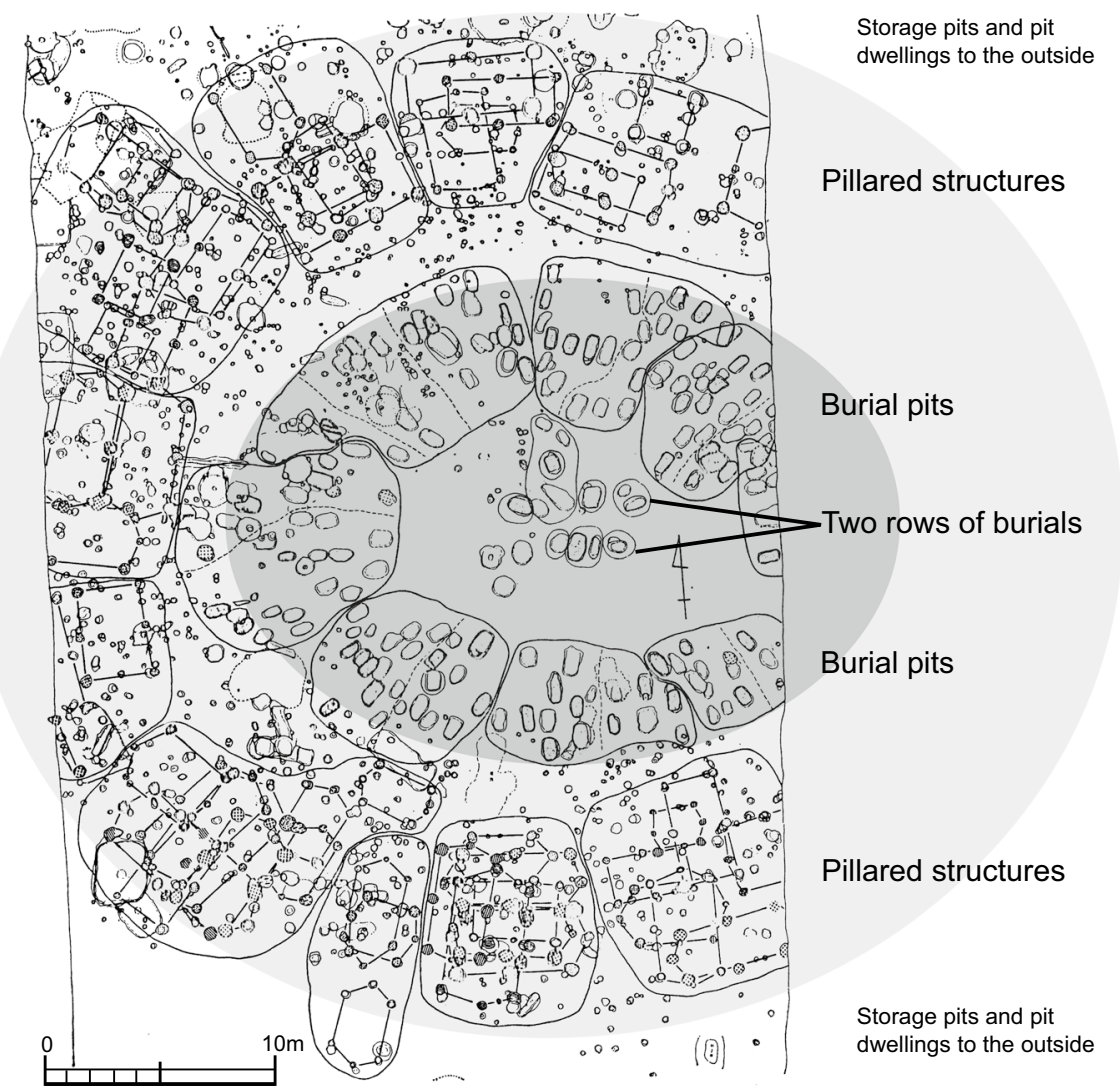

Fig. 2 The Nishida site (the Middle Jomon phase), Iwate Prefecture (from Iwate Prefectural Board of Education 1980). Pillared buildings are likely to have been either storage facilities or, a speculative inference has it, mortuary practice-related facilities, such as for excarnation

inhabited, with the occupants relying heavily on particular subsistence resources, but it is also possible that they were inhabited during a particular season or seasons when people, who otherwise lived at the bases, visited to procure season-specific resources.

The concentric circular zones comprising the base settlements are commonly divided into radial segments (Fig. 2), leading to the inference that clan/lineage-type corporate groups, comprising a larger corporate grouping (which some might call 'tribal') lived together at the base settlements during certain periods of the year, burying their dead, conducting communal ceremonies, and exchanging goods and people; at other times such groups lived separately from one another at their respective satellite settlements (e.g. Mizoguchi 2002, pp. 102-105; cf. Taniguchi 2005). It has also been pointed out that at some examples of such large bases, where the radial segments are marked by stone settings (e.g. Miyao 1999), certain orientation axes marked by them point to the rising and/or setting of the sun on the solstices and/ or equinoxes, or to prominent landscape features such as mountain peaks (Miyao 
1999). Such spatial divisions, their markings, and their connection with prominent landscape features and with the movement of heavenly bodies, would have enabled the generation and maintenance of the expectations, and those connections would have constituted the way in which the becoming of those who inhabited the base type settlements and the material items they used (including the pottery) unfolded. We shall come back to this point below.

In terms of the reproduction of communication, the mobile lifeways of the Incipient and Initial Jomon phases_or Earlier Jomon period (hereafter EJ)—would have confined the daily horizon of communication to individual band-like groups in which the daily face-to-face confirmation and maintenance of the expectations of a common understanding would have been possible. From the final phase of the Initial Jomon period onward, datable around $5000 \mathrm{BC}$, in what we call the Later Jomon period (hereafter LJ) in this paper, the sharing by the whole community-occupying a territorial unit and possibly comprising a non-residential corporate, or 'tribal', grouping-of the expectations would have become a prominent difficulty, or an 'issue', to be coped with. The procurement of seasonal resources at different locales, probably undertaken by differently organised groups in terms of age and gender composition, and possibly comprising more than two corporate group segments (some might prefer to call them 'lineages' or 'sub-lineages': see Mizoguchi 2002, pp. 102-105; cf. Taniguchi 2005), would have resulted in the formation of mutually distinct seasonal communicative domains in which different sets of communication systems were reproduced (Fig. 3). Furthermore, the natural environmental items/ resources that were encountered, procured and processed would also have been different between such domains, respectively forming distinct seasonal resource locales (Fig. 3). All these factors would have made the sharing of the expectations amongst the members of a territorial, non-residential corporate grouping extremely difficult.

In order to overcome the difficulties involved in the sharing of the expectations across such communicative domains, and amongst the members of a whole community, the generation of a sense of 'connectedness' or 'oneness', which is well captured by the concept of 'mystical participation' proposed by the French philosopher-sociologist-anthropologist Lucien Levi-Bruhl (1923), would have been essential (Fig. 3). The concept of 'mystical participation' can be understood thus: certain categories of everything - that is, human beings, animals, plants, landscape features and, importantly, certain feelings, words and concepts-constituting the lifeworld are causally connected to one another. Such feelings and perspectives would have been generated and enhanced through moving from one resource locale/communicative domain to the next regularly and repeatedly, encountering different environments, and coping with different sets of uncertainties and the risks generated by them (Fig. 3). Such experiences, sequential and cyclical at the same time, would have made all feelings, words, concepts, and material differences metaphorically connectable and mutually transformable (Fig. 3). I would argue that it is the sense and feeling of oneness and mystical participation (Levi-Bruhl 1923) that characterizes the way that human individuals and non-human entities and/or abstract phenomena-including not only material items but also animals, plants and feelings, notions and concepts—opened-up each other's potentialities in the LJ. 

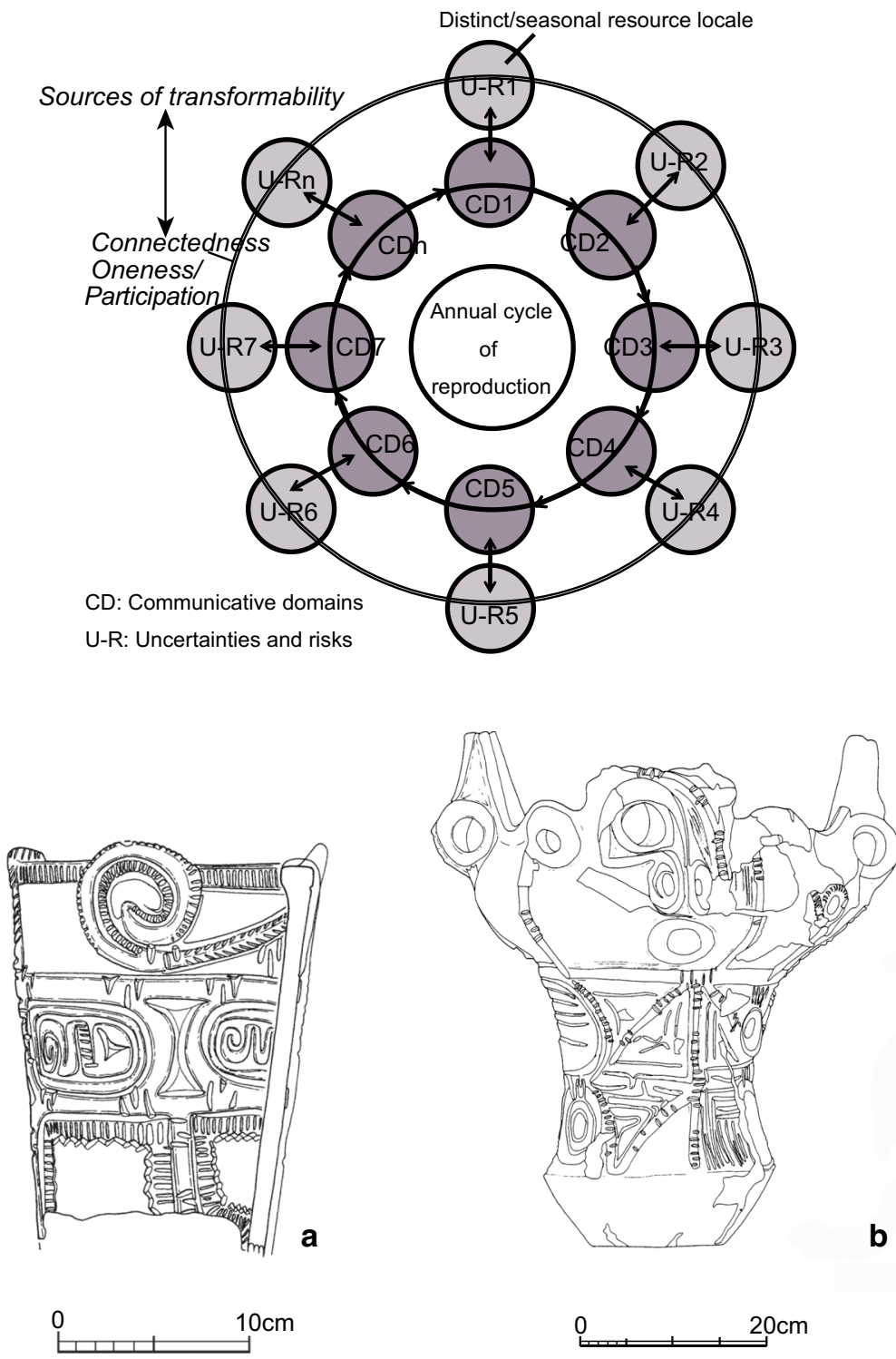

Fig. 3 Differentiation and distribution of communicative domains of the Later Jomon, a diagram: a Early Middle Jomon (Katsusaka style) vessel from Pit dwelling No. 33, Tama new-town No. 245 site (from Tokyo Metropolitan Centre for Buried Cultural Properties 1988, p. 135, Figure 110); b from Shakado site, Yamanashi Prefecture (from Yamanashi prefectural buried cultural properties centre 1987, Figure 186-1)

For instance, repetitive motions employed for the execution of design patterns characterize the material culture of the Later Jomon period. From the beginning of the LJ onward (from around $5000 \mathrm{BC}$ ), the surface of pottery began to be divided into regularly-spaced design panels which were filled with repeat patterns; a variety 


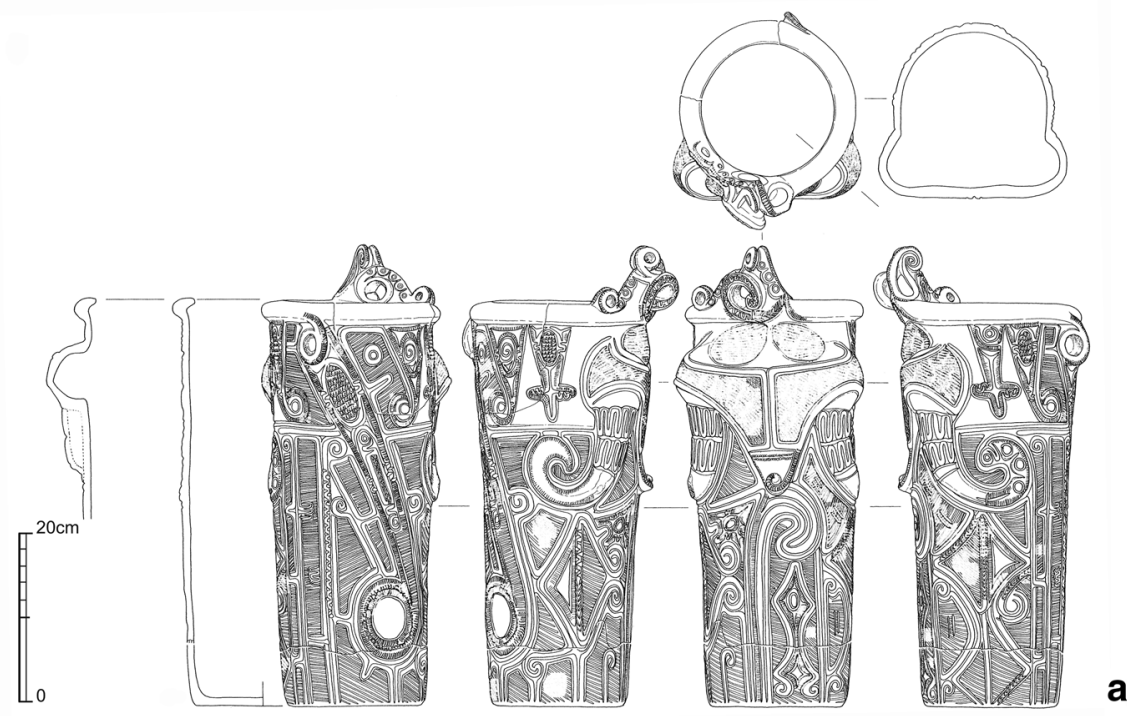

a

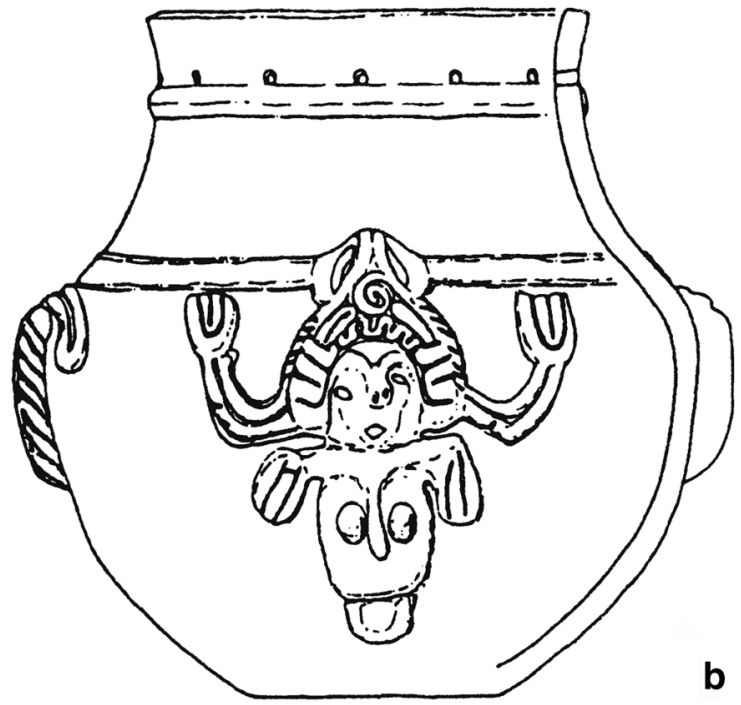

Fig. 4 Jomon pottery (the Early Middle Jomon phase): a with the contours and boundaries between various creatures/entities utterly blurred. Pit dwelling No. 32, the 3rd excavation, Tonai site, Nagano prefecture (from Higuchi, et al. 2011, Figure 92); b with the depiction of a chimera-like human-something Height: $26.5 \mathrm{~cm}$. Hayashioji site, Kanagawa prefecture (from Taniguchi 2005, Figure 7-1)

of living creatures, some quite fantastic, were often represented, not by inscribing with pointed tools but by the addition of clay cords (or ridges) (Figs. 3 and 4). Some refined specimens had their surfaces completely covered/inhabited by (the representations of) different creatures and by the features of unknown (to us unidentifiable) 
identities (Figs. 3 and 4). They were represented as distinct entities, but they occupied the design horizon/panel side by side with no gap in between. The design panels on the body of a pot were quite often spatially matched and marked by wavy units of the rim (Fig. 3b); sometimes protrusions were added. There are rare specimens that explicitly, but in a highly abstract manner, represent the human (female) body (Fig. 4b). In some cases, creatures were attached as if emerging from the inside of the vessel (Fig. 4a); cases like this suggest that the whole vessel was created as embodying a world inhabited by those creatures.

It is as if the lifeworld of the potters were literally recreated and packed on to the walls of the pots; rhythmic and recurrent movements and their tactile experiences, two of the basic elements of Later Jomon living-in-the-world experience, were captured and represented by the repetitive motions involved in creating creatures and/or natural features by adding clay cords to the pottery surface, which themselves mimic the motion of the natural world (including one's body). Particular elements of the lifeworld that would have been perceived to be significant in one way or another for its very existence, were not signified with mere visual signs but with something that concretely embodied/materialized those elements themselves.

At this point, it would be useful to compare what we have on the pots with the settlements of the period, the base settlements (see above) in particular (Fig. 2). In the latter, people buried their dead, encountered their ancestors, stored, processed and consumed foods, brought in raw materials and produced tools, met one another, married, gave birth, and died. Quite often the central burial area of the large base settlements of the period was surrounded by storage facilities (Sasaki 2002). The dead were juxtaposed with foodstuffs that themselves had been hunted/procured and consumed/killed, and then regenerated through sustaining the life of people. In other words, the base settlements of the period formed a locale/container where the things comprising the lifeworld transformed their states in a cyclic manner, following the cycle of death and regeneration.

It is surely significant that the regularly-spaced wavy rim of the pottery (see Fig. 3b) emerged in the beginning of the LJ, and that that very phase also witnessed the emergence of the circular, base settlements, whose character as a locale was illustrated above. A fair ratio of the pots with regularly-spaced wavy rims and characteristic motifs, illustrated above, are cooking jars (Kobayashi 1994, pp. 133-135). In those pots, plants and/or animals, once alive but collected or hunted, were cooked and transformed to be consumed by people for the sustenance of their lives and, in a way, regenerated their lives. And that cycle of transformation/death and regeneration took place in a pot, that itself formed a 'micro locale', which was segmented and marked by the waves and protrusions of the rim, like the circular settlements were (see Figs. 2 and 3b). In other words, the waves and protrusions of the rim of a pot would have embodied how those who inhabited the base settlements organized themselves spatially, inhabited the settlement-scape and the landscape, and experienced their lifeworld through encountering various creatures. And the creatures that inhabited that micro locale were depicted in a rhythmic, hence cyclical, manner. The potter brought forth the pottery as the lifeworld itself, and that lifeworld opened itself up in the forms of and on the pottery - both through the mediation of 
the experience of dwelling in the large base settlements, probably experienced as the centre of the lifeworld.

Various sexual-organ-shaped items also characterized the LJ, often made of fine stones with skin-like smoothness and touch, and produced through repetitive and quite persistent pecking and polishing. Many examples of the phallus-shaped items bear the trace of repetitive pecking and rubbing as use-wear as well (e.g. Taniguchi 2012). These observations suggest that both the production and the use of those items mimicked/enacted sexual intercourse as rhythmic and repetitive bodily motions and that such enactment was perceived to be connected to, and the same as (as far as the belief of mystical participation went), actual sexual intercourse and hence to cause the reproduction of new life. The use (as well as production) of those items most often took place at the base settlements, the locale where, as illustrated above, the mystical participation (Levi-Bruhl 1923) between various living beings, material beings and material differences was realized. This occurred through the recursive/cyclical experience of, participation in, and reflection on, death and the regeneration of life by the settlement's inhabitants. Through the experience of dwelling together at the bases, the belief that the mimicking/enactment of sexual intercourse in the production and use of sexual organ-shaped items caused the reproduction of life in general would have spread across the lifeworld.

In describing the way in which human and material beings mutually opened up their potentialities, it is probably misleading to use words/concepts such as meaning and representation. What we are witnessing is not the reduction of the complexity of the natural and the encultured world by signifying its elements with clearly bounded/defined material differences; rather, what we see here is participation in the web of transformative relations between things, between actions, between things and actions, and between things, actions, concepts, and feelings by causing those elements of the world to materialize in the form of mutual becoming.

This one-ness and participation-based lifeworld, and the mutual opening up of the potentialities of human individuals and material beings were comprised of and constituted by a unique combination of factors (see item number 14 of the itemized points of Luhmann's theory of communication systems above) concerning: (a) the coexistence of a range of communicative domains (in which distinct sets of communication systems were reproduced); (b) the frequencies and the rhythms of their occurrence; (c) the uncertainties and risks they generate; and (d) the material differences ranging from material items of various scales and natures to notions and concepts taking the form of neuronal-material phenomena (Fig. 3) (cf. Malafouris 2013). This unique assemblage (see Table 1 below) (cf. De Landa 2006), constituting the context in which the mutual opening up of the potentialities of human individuals and material beings took place. This assemblage was drastically transformed in the Yayoi period that followed. 
Table 1 The Jomon assemblage

Jomon assemblage

\begin{tabular}{ll} 
Communicative domains & $\begin{array}{c}\text { A number of them differentiated by seasonal resource procurement and } \\
\text { related activities and horizontally distributed }\end{array}$ \\
Uncertainties \& risks & $\begin{array}{l}\text { Generated at each of the communicative domains differentiated } \\
\text { Perception of reality }\end{array}$ \\
Material culture & $\begin{array}{l}\text { Senses of oneness and mystical participation } \\
\text { Embodying material differences, concepts and human beings in the mode } \\
\text { of mutual participation and transformation for coping with horizontally } \\
\text { distributed uncertainties and risks }\end{array}$ \\
Characteristics & $\begin{array}{l}\text { Fantastic creatures, including chimera-like ones, with ambiguous contours, } \\
\text { created with clay cordons }\end{array}$ \\
\hline
\end{tabular}

\section{The Yayoi Period}

The Yayoi period, marked by the introduction from the southern coastal region of the Korean peninsula of systematic rice paddy field agriculture during the first half of the first millennium BC, saw the firm establishment of a sedentary way of life, rapid population increase, the budding-off of new hamlets from established villages, and the formation of regional settlement systems across wide areas of western Japan, each of which comprised a large settlement that increasingly acquired 'central-place' characteristics, and a number of smaller satellite settlements-a pattern formally similar to the preceding one, but on a much more stable, extensive, regional scale (Mizoguchi 2013, pp. 102-105).

Let us remind ourselves here that the Jomon people were involved in different production and/or procurement activities from one season to the next, and the groups involved in the procurement of different natural resources would have been differently organised in terms of gender, age, and kin affiliations according to the nature and character of what was procured, where and how. Those observations suggest that the Jomon community had to cope with such uncertainties as the annual availability of different subsistence resources, each of which had its unique temporality and spatiality, and that those issues were spatio-temporally distributed wide across their lifeworld (Fig. 3). That means that different uncertainties and risks were experienced and coped with at a number of different spatio-temporal domains in the Jomon period, and it can be safely inferred that those domains would have formed distinct communicative domains (for the definition of the concept, see the previous section) as well (Fig. 3). The paddy-field rice-farming cycle consists of a sequence of activities mostly undertaken in the paddies themselves and in their vicinities almost throughout the year, which meant that most of the significant uncertainties and risks experienced and coped with were within a fairly limited, confined spatial domain. As wide a range of uncertainties and risks as that in the Jomon period would have been experienced in the annual rice-farming cycle, but those would have been perceived to be unified under a single issue and objective: how to obtain a good rice harvest in the autumn. That would have led to the generation of a unified single communicative domain (Fig. 5), dominant over all the other domains of the 

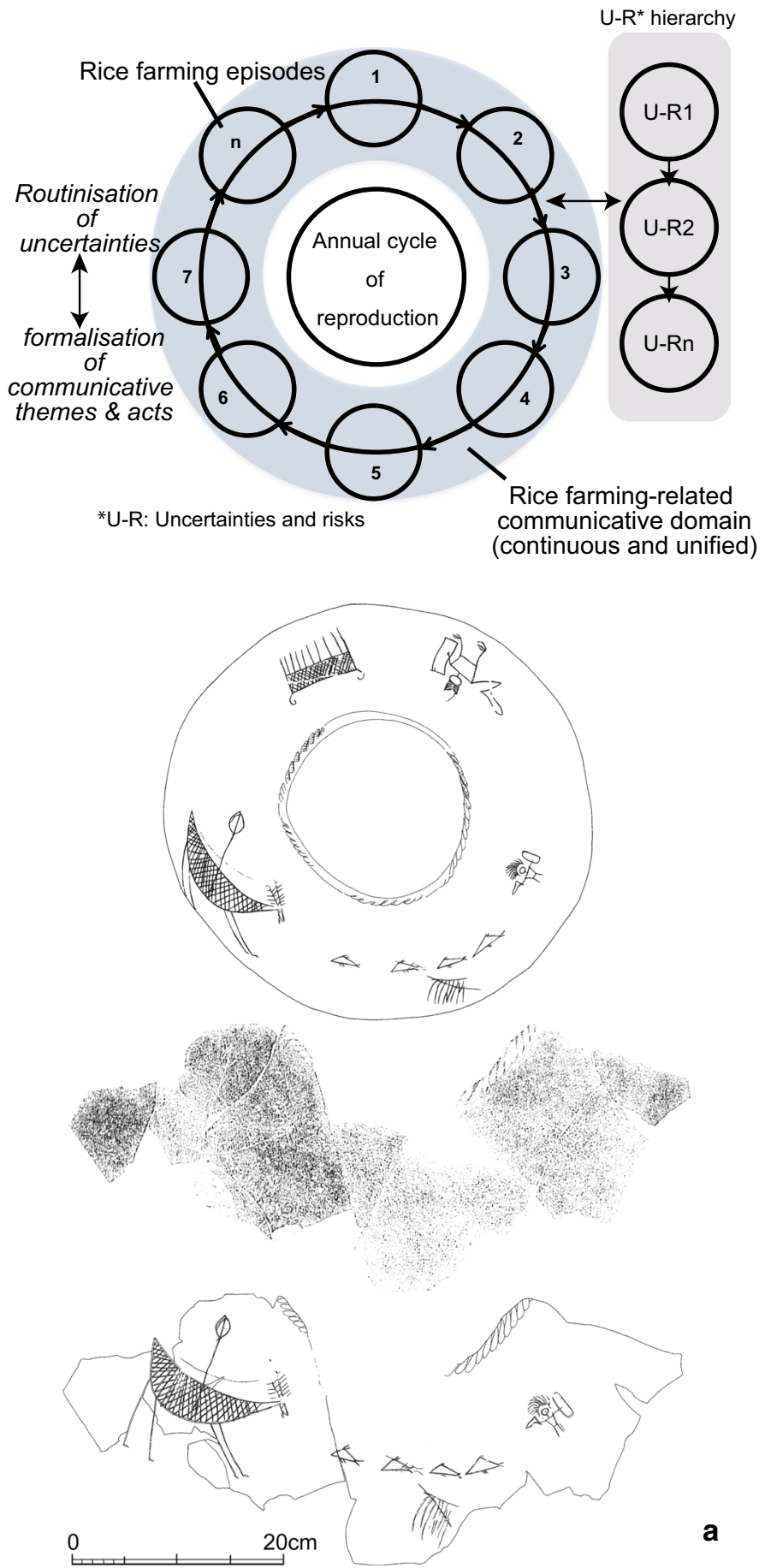

Fig. 5 Differentiation and distribution of communicative domains of the Yayoi period, a diagram: a Late Middle Yayoi (Yayoi IV phase) vessel from Shimizukaze site, Nara Prefecture (from Fujita 2006, p. 79, Figure 3) 
lifeworld, differentiated and bounded by increasingly fixed and well-defined material differences exclusively relevant to the issue and objective of obtaining a good rice harvest. And the uncertainties and risks experienced and coped with in that communicative domain would have become routinised, and the contingencies generated by them inevitable. Naturally, the skills and technologies to cope with such predictable inevitabilities, the destruction of paddy irrigation systems by a typhoon, droughts, and so on, for instance, would have been formed, and communications involved in them would have become routinised, well-defined for certain purposes, and formalized (Fig. 5).

As the Yayoi period agricultural innovations prompted rapid population increase and the consequent splitting of localised corporate groupings in the form of the budding-off of corporate group segments to new locations suitable for constructing new rice paddies, so it would have made the getting together of all members of individual corporate groups increasingly difficult (Mizoguchi 2013, pp. 119-135).

Now we have two trends being enhanced concurrently: one, the increasing formalisation of technologies with which to cope with certain contingencies generated as risks associated with the rice paddy-field farming way of life, and the other, increasing difficulty in the reproduction of the expectations necessary for the reproduction of intra- and inter-corporate group communications. The combination of these trends appears to have caused some important changes in the way in which human and material beings mutually opened-up their potentialities. In terms of comparison with the earlier, Jomon, pottery the disappearance of human, animal and other fantastic figures formed by adding clay on pottery surfaces, and the emergence in the Yayoi, instead, of inscribed pictorial figures is a prominent and, as argued below, highly significant development (see Fig. 5a).

The inscription of pictorial figures on the surface of specific pottery shape-types, on bronze, and other ritual implements began in the early Middle Yayoi period (around 200/100 BC), and reached its zenith in the second half of the Middle Yayoi period (around AD 1) (Fig. 5a). Inscribed figures on these media include animals (both mammals and amphibians), fish, birds, insects, humans, material items and buildings (see Mizoguchi 2013, pp. 166-180).

Like its Jomon equivalent, Yayoi pottery itself was a significant medium for the expression of material differences. We have numerous examples in which a single inscribed figure was made on the surface. We also have examples, less common than the above, in which some inscribed figures, often depicting different entities, were juxtaposed as if depicting a certain episodic scene. Finally, there are rare cases in which such depictions of episodic scenes were juxtaposed on the surface as if forming a materialized sequential narrative (see Fig. 5a as a pottery example). That almost all the singly depicted entities made their appearance in the depiction of an episodic scene or a sequence of episodes suggests that the singly inscribed entities would also have represented, or at least evoked, a whole episode of a narrative structure (Harunari 1991). In other words, those inscriptions made on the surface of pots singly or in combination would have represented a well-defined system of meaning.

One significant element of those inscribed figures is that they include some definite depictions of priest-like figures apparently conducting ritual acts (Fig. 5a). In some such examples, priest-like figures hold a halberd and a seal, suggesting that 
the rituals included mock battles (an inference supported by the presence of various types of weapon-shaped items made of wood: see e.g. Okayama Municipal Board of Education 2005). Ethnographic examples from Asian rice-farming areas show that such mock battles were conducted against evil spirits disrupting the growth of rice, or to encourage the growth of rice by threatening its spirit (e.g. Iwata 1970). In any case these inscribed figures are likely to depict actual scenes of ritual activities. This seems to me to mark a fundamental departure from the way that human- and material beings had opened up their potentialities to one another during the preceding Jomon.

First of all, those inscriptions were made on the smoothed surface. In the case of Jomon pottery, such a surface was (perceived as) dwelt in/inhabited by creatures, suggesting that it was created and perceived as a micro-locale/microcosm itself, in which creatures inhabiting the lifeworld and features comprising the physical structure of the lifeworld were recreated. In stark contrast to that, the Yayoi pottery surface functions as a blank canvas on which signifiers of something else, including not only entities such as creatures and features but also actions such as ritual conduct, were inscribed.

The 'inscription-as-signification' would not have generated an ever-growing network of mutually mystically-participating people, plants, insects, animals, topographical features, and so on, but rather restricted the potential growth of the network of meaning and reduced the complexity generated by the possibility of polysemous readings. Ritual is an intentional act with clear objectives, and often designed to intervene in a particular chain of causes leading to the realization of a particular state of an element/elements of the lifeworld, even if the manner of its execution is often traditionalized and routinized. If we call the former-the mode which characterizes Jomon pottery - the 'expansion/shamanistic' mode, and the latter-the mode that characterizes Yayoi pottery-the 'reduction/priestlike' mode, the expansion mode embodies symmetrical relations between people, plants, insects, topographical features, and so on, whereas the reduction mode signifies asymmetrical relations between human beings and the other beings that are depicted, in which human beings are given a privileged position. Priest-like figures are depicted there to be perceived to perform, on behalf of others, the acts which influence the way others are depicted, that is, animals, insects and so on, and how they behave/live their lives. And this asymmetry would have been extended to the relationship between those who displayed the pots and those who were shown them. The former would have brought the pottery into a certain setting with the intention of displaying the causal connection between the act and its supposed outcome(s), and the latter came into that setting and saw that depiction of the cause-effect relationship; the latter are likely to have perceived that relationship as a result of the effort of the former, leading to the generation and consolidation of hierarchical social relations.

Inscription is a type of reductive bodily action that is opposed in some way to the spirit of mystical participation; inscription cannot be connected to any concrete bodily movements such as sexual intercourse but only to itself, and is a uniquely specifically purposeful act, suitable for signifying something specific. Indeed, inscribed lines are suitable for bounding things and marking a space out 
of an undifferentiated, and potentially unlimited, horizon. In that sense, inscription is an act uniquely suitable for reducing the complexity of the world, comprising every thing (both living and non-living) and every concept. In other words, it is unfit for expanding the web of connections between things, between concepts, between things and concepts, and between things, concepts and acts by blurring differences between them-that is, all that is emphasized in the earlier, Jomon pottery: the above-mentioned expanding web of connections supporting the sense of oneness, which, as I argued above, was the ultimate backbone of the reality of the Jomon. The fact that, in the Yayoi period, inscription and the 'reduction' mode that crept into the horizon of material expression suggests that the reality of the lifeworld changed in a fundamental way. What happened?

It is particularly interesting to point out that the pots on which a scene of ritual conduct was inscribed were themselves those that would have been used on ritual occasions, meaning that the inscribed entities signified what was to be conducted in the presence of the pictorial representation of that very conduct. It suggests that the inscription and the depicted scene instructed those who were co-present with the pot with its inscribed entities concerning how to act. The ritual conduct itself signified a prayer for something, and that signification would have relied upon the concept of, or belief in, mystical participation. However, the inscription signified the meaning of the ritual conduct by depicting the visual appearance of such conduct itself. Here we can see the shift in the nature of material culture from the embodiment of a diverse range of what is (perceived to be) significant for the continuation of the lifeworld to the signification of an increasingly limited range of entities and well-defined human acts (perceived to be) significant for the well-being of the lifeworld. By this point in the Yayoi period, material culture is used to instruct people concerning how to behave and communicate and how to share what specific expectations.

\section{Concluding Remarks}

In the transition from the Jomon to the Yayoi periods, the way in which human and material beings mutually opened up their potentialities was significantly constituted and transformed through the transformation of the way communication took place and was sustained by coping with issues that the communication itself-as well as the environment, both social and natural-generated. Human individuals, plants, animals, material items including topographic/landscape features and all the material differences were networked and mutually influenced their states of existence differently between different communicative domains (in each of which a distinct set of communication systems were reproduced), and the way they were networked would have been differently stabilized/oscillated/transformed according to the different frequencies and rhythms in which they took place, and according to the different degrees of connectedness between a certain communicative domain and a certain locality.

The long-term history of the mutual opening up by human and material beings of their potentialities from the Japanese Jomon through the Yayoi periods 
witnessed, as mentioned above, a shift from one combination/assemblage (cf. De Landa 2006) of the factors (concerning the range of communicative domains coexisting; the frequencies and the rhythms of their occurrence; the uncertainties and risks they generated; the material differences ranging from material items of various scales and natures to concepts and notions) to another.

The Jomon assemblage (Fig. 3 and Table 1) consisted of a wide range of communicative domains (differentiated by different subsistence resource-procurement activities), and each of these domains had to cope with a unique set of uncertainties and risks generated by the unique group organization and structure (in terms of gender and age groupings; the unique behavioural pattern of the animal/plant to be procured; the unique set of material differences; the weather; the topography of the terrain; and so on) that the group had to deal with. Such assemblages networked the human and material agents and all the other material differences involved in the reproduction of those communicative domains in a way which flexibly expanded the range of entities and factors to be networked and blurred their causal connectivity. Human and material agents, and all the other material differences, opened up their potentialities in a manner which can be characterized as 'participation', and probably 'shamanistic'; everything involved in the reproduction of the extant communicative domains was understood to be the cause of everything else. Therefore, the production of material items itself appears to have been undertaken as the creation/reproduction of a certain part/element of the world, and the bodily actions involved in the production, and human beings, animals and other creatures depicted on material items, all had something to do with the reproduction of life: the bodily actions captured elements of sexual intercourse, and the creatures depicted embodied the death and regeneration of life.

The range of different communicative domains of which the Yayoi assemblage (see Fig. 5 and Table 2) consisted would have been as wide as that of the Jomon equivalent. However, the adoption of rice paddy-field agriculture opened up a single year-round communicative domain that dominated the spatio-temporal organization of all the communicative horizons forming the lifeworld. The issues the communicative horizons had to deal with became hierarchized as the uncertainties generated by the failure of certain elements of rice farming and other activities to sustain the society would have become hierarchized according to the different degrees of damage they caused to the sustaining of the society (Fig. 5: U-R hierarchy). Accordingly, uncertainties_or 'risks' - became causally predictable, and the communicative domains which had to deal with certain risks became formalized and the material items mobilized in such horizons came to bear instructional signs for the exact conduct of formalized (ritualistic) communicative acts. Hence the surface of the pottery became a blank canvas where detailed signs depicting the conduct by priest-type individuals of ritual actions or narratives of causal implications for coping with uncertainties were inscribed.

We should not make the mistake of assuming that this shift was universally correlated with a shift from the hunting-foraging to the agricultural way of life. This shift should rather be correlated with the shift from a lifeworld consisting of a wide range of communicative domains distributed differently across the cycle of the year with their interrelationship horizontally/non-hierarchically constituted to a lifeworld 
Table 2 The Yayoi assemblage

Yayoi assemblage

Communicative domains A single domain, consisting of a sequence of episodes, differentiated by annual rice farming cycle

Uncertainties \& risks Generated as a hierarchy of risks of different degrees of seriousness

Perception of reality Well-defined risks responded to and treated in routinsed and formalised manners

Material culture Signifying/instructing how to behave in coping with hierarchically distributed, well-defined risks

Characteristics Inscribed human, animal and insect figures and buildings depicting episodic scenes including ritual conduct

consisting of hierarchically distributed communicative horizons amongst which one or a small number were dominant in terms of the way they were causally connected. The latter made the signification/instructional potentiality of material culture come forth, whereas the former made the material potentiality of embodying and encouraging mutually participatory connections/networkings come forth. In other words, the Jomon assemblage in which human-material relations were situated and constituted was internally symmetrical in terms of causalities (Table 1), whereas the Yayoi assemblage was internally hierarchical in terms of the signification of certain intentions imposed by certain individuals/groups (Table 2).

In conclusion, I should like to emphasize that the examination of how material culture transformation was correlated with the shift from a lifeworld consisting of a wide range of communicative domains distributed differently across the cycle of the year, with their interrelationship horizontally/non-hierarchically constituted, to a lifeworld consisting of hierarchically-distributed communicative horizons, amongst which one or a small number were dominant in terms of the way they were causally connected, is a meaningful and concrete-enough way to investigate the way human beings and material culture mutually open-up their potentialities and transform them.

Acknowledgements I would like to thank two anonymous reviewers, whose critical comments on the initially submitted manuscript enable me to improve my grasp of the issues this paper intends to tackle and the way I present the outcome of the analysis. I should also like to take this opportunity to express my gratitude to Professor Timothy Taylor, the Editor of the Journal, for his patience and skillful, detailed guidance throughout the process. This work was supported by JSPS KAKENHI grant JP17K03211.

Open Access This article is licensed under a Creative Commons Attribution 4.0 International License, which permits use, sharing, adaptation, distribution and reproduction in any medium or format, as long as you give appropriate credit to the original author(s) and the source, provide a link to the Creative Commons licence, and indicate if changes were made. The images or other third party material in this article are included in the article's Creative Commons licence, unless indicated otherwise in a credit line to the material. If material is not included in the article's Creative Commons licence and your intended use is not permitted by statutory regulation or exceeds the permitted use, you will need to obtain permission directly from the copyright holder. To view a copy of this licence, visit http://creativecommons.org/licen ses/by/4.0/. 


\section{References}

Barrett, J. C. (1988). Fields of discourse: Reconstituting a social archaeology. Critique of Anthropology, $7(3), 5-16$.

Binford, L. (1980). Willow smoke and dogs' tails: Hunter-gatherer settlement systems and archaeological site formation. American Antiquity, 45(1), 4-20.

De Landa, M. (2006). A new philosophy of society: Assemblage theory and social complexity. London: Bloomsbury.

Deleuze, G., \& Guattari, F. (1987). A thousand plateaus: Capitalism and schizophrenia. Minneapolis: University of Minnesota Press.

Fujita, S. (2006). Kaiga-doki no mikata sho-ko: Te wo ageru jinbutsu to tate ka wo motsu jinbutsu (A thought on Yayoi vessels with pictorial representations: Figures with raised arms and figures holding a halberd). In H. Shtara (Ed.), Genshi-kaiga no kenkyu (A study of ancient pictorial representations) (pp. 73-84). Tokyo: Rokuichi Shobo. (In Japanese.)

Gell, A. (1998). Art and agency: An anthropological theory. Oxford: Clarendon.

Giddens, A. (1984). The constitution of society: Outline of the theory of structuration. Cambridge: Polity Press.

Habermas, J. (1984). The theory of communicative action. Boston: Beacon Press.

Habu, J. (2004). The ancient Jomon of Japan. Cambridge: Cambridge University Press.

Harman, G. (2011). The quadruple object. Alresford: Zero Books.

Harunari, H. (1991). Kaiga kara kigo he (From pictorial representations to signs): Yayoi-jidai ni okeru noko-girei no seisui (Changes in farming-related rituals in the Yayoi period). Bulletin of the National Museum of Japanese History, 35, 3-65. (In Japanese.)

Heidegger, M. (1993 [1960]). The origin of the work of art. In D. F. Krell (Ed.), Heidegger: Basic writings (pp. 89-139). London: Routledge.

Hicks, D. (2010). The material-cultural turn: Event and effect. In D. Hicks \& M. C. Beaudry (Eds.), The Oxford handbook of material culture studies (pp. 25-98). Oxford: Oxford University Press.

Higuchi, S., Takafumi, K., \& Kobayashi, K. (2011). Tonai: Senshi-tetusgaku no chushin (The Tonai site: The centre of prehistoric philosophy). Fujimi: Fujimi Town Board of Education. (In Japanese.)

Hodder, I. (1982). Symbols in action: Ethnoarchaeological studies of material culture. Cambridge: Cambridge University Press.

Hodder, I. (2012). Entangled: An archaeology of the relationships between humans and things. Oxford: Wiley.

Imamura, K. (1996). Prehistoric Japan: New perspectives on insular East Asia. London: UCL Press.

Iwata, K. (1970). Sekai no shukyo, Vol. 10: Kami no tanjo (Religions of the world, Vol. 10: The birth of the gods). Tokyo: Tankosha. (In Japanese.)

Joas, H., \& Knöbl, W. (2009). Social theory: Twenty introductory lectures. (Translated by Alex Skinner.) Cambridge: Cambridge University Press.

Kani, M. (1993). Jomon jidai no setorumento sisutemu (The settlement systems of the Jomon period). Kikan kokogaku (Archaeology Quarterly), 44, 77-81. (In Japanese.)

Kobayashi, T. (1994). Jomon-doki no kenkyu (The study of the Jomon pottery). Tokyo: Shogakkan. (In Japanese.)

Kobayashi, T. (2004). Jomon reflections: Forager life and culture in the prehistoric Japanese archipelago. Oxford: Oxbow Books.

Kudo, Y. (2012). Kyusekki-Jomon-jidai no kankyo-bunka-shi: Koseido hosyaseitanso nendai sokutei to kokogaku (The environmental-cultural history of the Palaeolithic and Jomon periods: High-precision carbon dating and archaeology). Tokyo: Shinsen-sha. (In Japanese.)

Levi-Bruhl, L. (1923). Primitive mentality. London: Allen \& Unwin.

Luhmann, N. (1995). Social systems. Stanford: Stanford University Press.

Luhmann, N. (2012). Theory of society (Vol. 1). Stanford: Stanford University Press.

Luhmann, N. (2013). Theory of society (Vol. 2). Stanford: Stanford University Press.

Malafouris, L. (2013). How things shape the mind. Cambridge: MIT Press.

Miyao, T. (1999). Shizen no naka ni torikonda jinko-kukan to shiteno kinenbutsu (The Jomon monuments as artificial spaces situated in the natural landscape). In T. Kobayashi (Ed.), Saishin Jomongaku no sekai (The frontier of Jomon studies) (pp. 61-73). Tokyo: Asahi Newspaper Co.

Mizoguchi, K. (2002). An archaeological history of Japan, 30,000 BC to AD 700. Philadelphia: University of Pennsylvania Press. 
Mizoguchi, K. (2013). The archaeology of Japan: From the earliest rice farming village to the rise of the state. Cambridge: Cambridge University Press.

Okayama Municipal Board of Education. (2005). Minamikata (Saiseikai)-iseki (Minamikata site Saiseikai location): Mokki-hen (Wooden implements). Okayama: Okayama Municipal Board of Education.

Olsen, B. (2010). In defense of things: Archaeology of the ontology of objects. New York: Altamira.

Olsen, B., Shanks, M., Webmoor, T., \& Witmore, C. (2012). Archaeology: The discipline of things. Oakland: University of California Press.

Sasaki, F. (2002). Kanjo-resseki to Jomon-shiki kaiso-shakai (Stone circles and the Jomon ranked society). In M. Anzai (Ed.), Jomon Shakai-ron (Studies in the Society of the Jomon Period) 2 (pp. 3-50). Tokyo: Dosei-sha. (In Japanese.)

Society of Yamato Yayoi Culture. (2003). Nara-ken no Yayoi-doki shusei: Honbun hen (The corpus of Yayoi pots from Nara prefecture: Description and consideration volume). Tawaramoto: Society of Yamato Yayoi Culture. (In Japanese.)

Taniguchi, Y. (2005). Kanjo-shuraku to Jomon shakai kozo (Circular settlements and the social structure of the Jomon period). Tokyo: Gakusei-sha. (In Japanese.)

Taniguchi, Y. (Ed.). (2012). Jomon-jidai no ishigami (The stone gods of the Jomon period). Tokyo: Rokuichi-shobo. (In Japanese.)

Tokyo Metropolitan Centre for Buried Cultural Properties (1988). Tama new-town No. 245 site. Tokyo: Tokyo Metropolitan Centre for Buried Cultural Properties. (In Japanese.)

Yamanashi Prefectural Buried Cultural Properties Centre. (1987). Shakado II: Zuhan-hen (Shakado site II: Figures and tables volume). Kofu: Yamanashi Prefectural Buried Cultural Properties Centre. (In Japanese.)

Publisher's Note Springer Nature remains neutral with regard to jurisdictional claims in published maps and institutional affiliations. 